\title{
USE AND EVALUATION OF A SHORT RANGE SMALL QUADCOPTER AND A PORTABLE IMAGING LASER FOR BUILT HERITAGE 3D DOCUMENTATION
}

\author{
A. Calantropio ${ }^{1 *}$, F. Chiabrando ${ }^{1}$, F. Rinaudo ${ }^{1}$, L. Teppati Losè ${ }^{1}$ \\ ${ }^{1}$ DAD - Department of Architecture and Design, Politecnico di Torino, Lab G4CH - Laboratory of Geomatics for Cultural Heritage \\ (alessio.calantropio, filiberto.chiabrando, fulvio.rinaudo, lorenzo.teppati)@polito.it
}

Commission I, ICWG I/II

KEY WORDS: Small UAVs, COTS sensors evaluation, Orientation and Calibration, 3D Models, LiDAR.

\begin{abstract}
:
The market of imaging and non-imaging sensors offers nowadays a wide range of products, which are constantly improving and growing. Given the recent advances in the miniaturization of devices for metric survey, and the relatively cheap COTS (Commercial Off The Shelf) solutions widely available, it is therefore crucial to optimally exploit, calibrate and evaluate the performance for 3D data acquisition of the new available devices. These issues are part of the latest research addresses of different Geomatics groups, with the aim to analyze and evaluate these new sensors, in order to discover their real potentialities which are not only connected to their interesting design, low price and small dimensions.

According to the final objective of the research, which is the realization of 3D metric survey of a Cultural Heritage site using different techniques and methods, one small UAV (Unmanned Aerial Vehicle) and a portable TLS (Terrestrial Laser Scanner) have been employed. The acquisition strategies and the processing methods are discussed, and the quality of the achievable results is analysed, together with an evaluation of the sensors and the outline of the best practices and use cases scenarios.
\end{abstract}

\section{INTRODUCTION}

As it is well known, the preliminary phases of any restoration project should include an extensive documentation and study of the object involved in the work. For example, in case of deteriorated facades in an historical building, the mapping of the deteriorations is one of the crucial preliminary operation to be achieved. Geomatics can support this part of the study in several ways: image and range-based sensors and techniques can support the subsequent analysis that need to be conducted with the data collected on the field. In these cases, it is important not only to reach a reliable level of metric consistency, but also to guarantee the integrity of the radiometric aspect, thus allowing materials and deterioration mapping, and their related subsequent analysis. For these reasons, it appears important to define strategies to better exploit the pros and cons of both image and range-based solutions and understand how to better operate with a data fusion approach. If, on one hand, TLS provide reliable geometrical information, on the other hand this method often lacks high quality radiometric data, due to the relatively low specs of the integrated RGB sensors. The new, low-cost and COTS sensors widely available on the market, allow nowadays to obtain data with a high consistent radiometric quality; this goes together with the advances in the LiDAR (Light Detection and Ranging) technology, providing devices more and more capable to achieve better results, compared to the recent past.

\subsection{Image and range based low-cost solutions for metric survey of Cultural Heritage}

The miniaturization of electronic components is a continuous process, which push the industries towards a development of ever-smaller instruments where different acquisition units are integrated.
The reasons that justify this trend are of different nature. Laser Scanner technology allowed, in the last decades of the past century, a different approach to the metric survey: the selection of the points useful to define the 3D model of the surveyed object could be postponed after the automatic acquisition of a sparse point cloud defined into an instrumental 3D Cartesian coordinate system, by using regular angular steps. The acquisition of digital images, oriented in the same coordinate system of the point cloud, allows the colouring of the point clouds and eases the interpretation of the point cloud itself and the subsequent segmentation as a necessary step towards a real modelling.

Thanks to the developments in matching algorithms, dense pointclouds are generated also by using a photogrammetric approach. In this case, the colouring is of better quality than the one previously described because metric and radiometric information come from the same primary data (the images).

Usually 3D metric survey of Cultural heritage assets usually does not require high accuracies, except in case of structural monitoring (Hess et al., 2018). or reverse engineering processes. In many cases (buildings or part of them, urban centres, natural landscapes), accuracies of about $2 \div 10 \mathrm{~cm}$ could be sufficient for each kind of intervention and support the generation of products at a scale of detail between 1:100 and 1:500 (documentation, restoration, valorisation, management), being the congruence the most important factor. These limited requirements open the possibility to use imaging sensors not directly designed for a photogrammetric application (e.g. amateur cameras). The images could be calibrated during the orientation process by obtaining results of sufficient precision and accuracy. These considerations justify the possibility to acquire photogrammetric blocks by using small UAV systems equipped by means of cameras with low resolution and small focal lengths like the ones today mounted on the UAV of less than $300 \mathrm{~g}$ weight. 
In the following paragraphs, two of these new integrated sensors will be described and tested to allow the comprehension of their potentialities and limits: the UAV Spark by DJI and the Imaging Laser Scanner BLK360 by Leica. The BLK360 represents an example of different sensor integration: beside the laser scanning system an HDR imaging system and a thermal sensor offer the possibility to merge data allowing different kind of survey with a strong metric meaning.

The registration of the different point clouds acquired by using terrestrial laser scanner instruments by using ICP approaches generally offers appreciable results but do not offer the possibility to check the accuracy of the survey. Also, by using high overlapping percentages the re-computing of the registration parameters by using Ground Control Points (GCPs) gives to the surveyor an evaluation of the real metric meaning of the acquisitions.

By using automatic digital photogrammetric approach, the point cloud could be generated by using the relative orientation of the camera poses and, in this case, a simple distance could offer the possibility to obtain a reliable point cloud in a local coordinate system. The use of GCPs in this case allow a refinement of the orientation into an existent coordinate system and a real appreciation of the precision of the survey: to check the accuracy a set of Check Points (CPs) is the traditional and more affordable strategy. (Russo et al., 2018). Therefore, in both approaches, the establishment of a control network is a mandatory task to offer the certification of the metric meaning of the survey.

After a brief introduction to the case study and its history, the sensors description, the acquisition strategies, the data processing methods, the possible integrations of the achieved results, and an evaluation of the data collected and processed are described. The final aim is the realization of a multi-scale $3 \mathrm{D}$ metric model for the documentation of the surveyed building.

A significant portion of the surveyed architectural object has been chosen as a test field for the different properties of the used sensors.

During the acquisition phase it is important to consider that ground survey is somehow limited due to the position of the instrument; talking about ground sensors (terrestrial close-range photogrammetry and 3D laser scanning) some parts of the surveyed object are not visible or shaded by projections of parts of the object itself. Some previous test performed by using UAV photogrammetry have proven to solve the issues of occlusions and shadow areas, overcoming the point of view limitations (A. Calantropio et al., 2018a).

The use of a photogrammetric approach for degradation monitoring purposes in Cultural Heritage field is comparable, in term of accuracy and quality of the results, with the laser scanning approach (Fassi et al., 2013).

BLK360 has been positively used also in the framework of educational activities for architectural survey purposes (Achille et al., 2018). TLS measurements, although being affected by measurement noise related to scanner mechanism, atmospheric conditions, object properties and scanning geometry, are accurate in the order of millimeters and can provide good quality results (Soudarissanane et al., 2011) and thus being used as a ground truth for photogrammetric models.

\subsection{The Case study, the Giuseppe Galliano barrack in Mondovì}

As it is reported before, the area of the survey is located in the city of Mondovì (about $80 \mathrm{~km}$ from Turin) in Piedmont (Italy) founded close to the end of the XII Century (1198).

In the analyzed area a first Church was built during the medieval period and, in 1501, the bishop Amedeo Romagnano decided to demolish this church and built a new bigger cathedral (St.
Donato), rotated in plan of 90 degrees respect the previous one. The engineer Ferrante Vitelli arrived in Mondovì in 1572, and started the Citadel construction (Figure 1, above) in the area that goes from the St. Donato's Cathedral until the eastern boundaries of the Mount.

After several transformations, a project dated 1681-1684 established to convert the cathedral into a barrack (Figure 1), thanks to the removal of the embankment, of the nave, and redoubling and lifting up the eastern part, in order to expand the part that was going to become barrack, reusing the bricks and the wooden attics.

The new buildings, called Giuseppe Galliano and Massimo Longa, are both in plastered brick walls and covered with tiles, incorporate the left and right aisles of the sixteenth-century cathedral respectively.

It is possible to find, moreover, the correspondences in the rooms next to the former presbytery, in the thorn wall and in the transversal partitions behind the pillars of the Massimo Longa barrack, probably in correspondence with the ancient side chapels, or in the building that once housed clergymen in the east. Some analysis determined the presence of the remains of the chapel to the right of the entrance of St. Donato (with an apse contained in the counter-façade), perhaps initially filled and covered with terrain for the formation of the embankment, and later incorporated in the wall next to the staircase of the barracks, still existing today in that position. In order test to the different sensors, only a part of the Giuseppe Galliano barrack has been considered in the present paper (Figure 2).

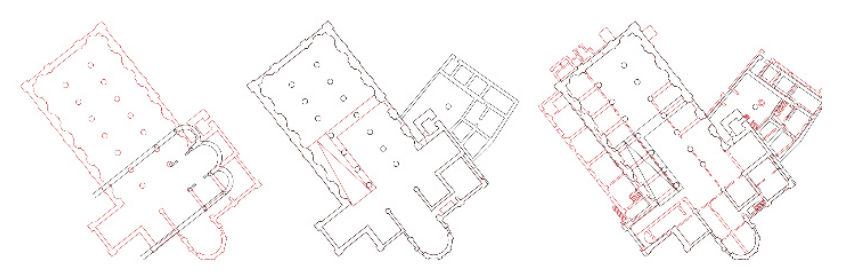

Figure 1. The evolution of the building (in red the new built part for each main step, below).

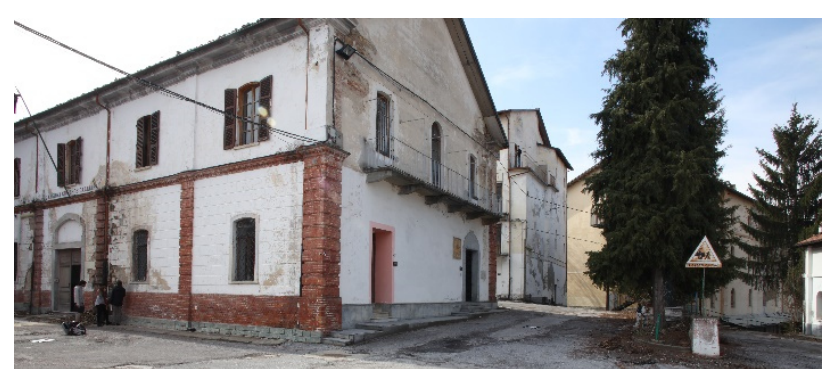

Figure 2. A view of a part of the Giuseppe Galliano Barrack in Mondovi.

The complex was selected as test area for teaching activities as well, that were carried out by the authors and other colleagues of Politecnico di Torino in the framework of the Course of "New Technology for Surveying and Drawing", a part of the Atelier of Restauration of the master's Degree of Architecture, for the realization of documentation analysis and restoration projects. This multidisciplinary course aims at the integration of different discipline that should contribute to realizing a conscious and sustainable restoration project. The use of cutting edge survey techniques is particularly stressed in the course, especially to build the knowledge of the building and to understand its evolution during time. 


\section{UAV PHOTOGRAMMETRY: SPARK (DJI)}

Spark (Figure 3) is a mini drone $(300 \mathrm{~g})$ developed and commercialized by DJI (Dà-Jiāng Innovations Science and Technology Co. Ltd.), with a 12 MP RGB camera and a sensor of $1 / 2.3$ " diagonal, it is capable to capture images in $4 \mathrm{~K}(4: 3)$ and videos in full $\mathrm{HD}(16: 9)$.
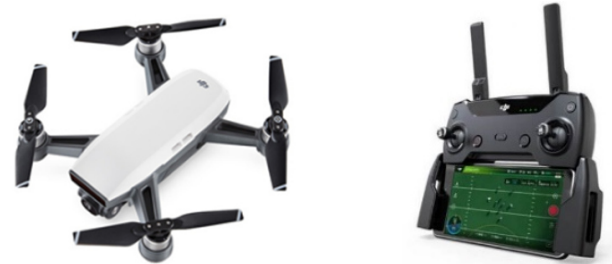

Figure 3. DJI Spark (left) and its remote controller (right).

The camera is stabilized using a 2-axis mechanical gimbal, with a controllable range of pitch going from $0^{\circ}$ to $-85^{\circ}$ (nadiral), main specifications of the platform are reported in the following Table 1.

\begin{tabular}{|c|c|}
\hline Camera model & DJI FC1102 \\
\hline Sensor & CMOS $6,17 \times 4,55 \mathrm{~mm}$ \\
\hline Effective pixels & $12 \mathrm{MP}$ \\
\hline Lens & FOV $81.9^{\circ} 4,5 \mathrm{~mm} \mathrm{f} / 2.6$ \\
& $(25 \mathrm{~mm}$ in $35 \mathrm{~mm}$ format equivalent $)$ \\
\hline ISO Range & $100-1600$ \\
\hline Shutter Speed & $2-1 / 8000 \mathrm{~s}$ \\
\hline Max image Size & $3968 \times 2976$ \\
\hline Photo Format & JPG \\
\hline Weight & $143 \times 143 \times 55 \mathrm{~mm}^{2}$ \\
\hline Size & \\
\hline${ }^{1}$ Take-off Weight & \\
${ }^{2}$ Size of the entire UAV & \\
\hline
\end{tabular}

Table 1. Principal specification of the DJI Spark.

While this platform was released specifically for a mass market distribution, it created the so-called category of the selfie-drone, it appears really interesting to stress the possibility of its use for photogrammetric purposes. One of the main limitations can be traced in the impossibility to perform an automatic flight due to the fact that the UAV does not support waypoints upload. Some third-part applications are under development to solve this issue, but they still need to be tested to ensure the safety during the flight and the quality of the results. Moreover, the range of the radio controller of the spark seems to be quite limited and is still an open issue that need to be verified. As it will be reported in the next paragraph, these issues can be partially solved using the Pix4D capture app that enable to achieve a semi-automatic flight, planning a flight and performing it manually.

\subsection{Acquisition strategies}

First of all, as usually, when a 3D metric survey is planned and performed, in the area several topographic vertexes need to be materialized in order to connect all the measurement and the acquired data to a common reference system. In the present research for the realization of the reference system, a mixed GNSS/ Total Station network was planned and measured. For the main network 4 vertexes were materialized and acquired using the GNSS with a rapid static configuration (45 minutes for each baseline). Furthermore, in order to adjust the network and to calculate the coordinates of the points in a known reference system, the observation connected to two permanent stations of the GNSS network of the Piedmont/Lombardy region were employed. Finally starting from those points, other vertexes were included in the network using traverses or inverse intersections since the position of this points didn't allow to use the GNSS for measuring it (occlusions, trees, walls etc.).

Starting from the main vertexes, in order to guarantee the metric control of all the acquired and processed data several artificial control points (markers) were positioned in the area (both on the walls for the LiDAR and photogrammetric acquisition or on the terrain for the UAV shooting). The coordinates of those markers were measured with traditional topographic solutions (side shot measurements). Once all the markers are positioned and measured is possible to start with the acquisition phase.

As it is well known, the current regulations regarding the use of UAVs in the European framework limits the possibility to employ bigger platforms (Stöcker et al., 2017); for that reason the use of lightweight (below $300 \mathrm{~g}$ ) UAVs is often a compulsory choice, especially in urban scenarios. Another reason that suggests the use of this kind of acquisition platform is the maneuverability needs related to the survey of the building facades; this is usually the case where surrounding buildings and narrow operative space makes important to prefer smaller and lightweight solutions.

In the presented case, the UAV acquisitions were realized adopting three different modalities (related with the platform characteristics and the desired Ground Sampling Distance): semiautomatic flight with Pix4D capture app at a medium altitude, manual flight with photogrammetric strips for the survey of the facades and, again, manual flight for the survey of the facades (but recording videos in order to extract and process frames in a second time).

As reported before, the only possibility to insert some automation in the acquisition phases was to use the Pix4D capture app with the manual flight modality. In this modality it is possible to select the acquisition interval (measured in meters of movement of the UAV both in the horizontal and vertical direction) between one shot and the subsequent. This semi-automatic modality allows the pilot to focus only on the flight of the UAV and on the plan of the photogrammetric strips, while the software will take care of acquiring the images with the desired interval. On the other hand, the drawback of this approach is the risk of collecting redundant data, especially in case of complex geometry of acquisition that requires a lot of movements of the UAV platform. To avoid this risk the most complex flights were achieved in fully manual mode. Table 2 shows the main characteristics of the flight performed with the DJI Spark.

\begin{tabular}{|c|c|c|c|c|c|}
\hline $\begin{array}{c}\text { Flight } \\
\text { ID }\end{array}$ & $\begin{array}{c}\mathrm{N}^{\circ} \\
\text { images }\end{array}$ & $\begin{array}{c}\text { Focal } \\
\text { length }\end{array}$ & $\begin{array}{c}\text { Camera } \\
\text { config. }\end{array}$ & $\begin{array}{c}\text { Shooting } \\
\text { distance }\end{array}$ & $\begin{array}{c}\text { Acquisition } \\
\text { time }\end{array}$ \\
\hline 1 & 230 & $4.5 \mathrm{~mm}$ & $\begin{array}{c}\text { Forward \& } \\
\text { Oblique }\end{array}$ & $5 \mathrm{~m}$ & $21 \mathrm{~min}$ \\
\hline 2 & 190 & $4.5 \mathrm{~mm}$ & Forward & $5 \mathrm{~m}$ & $16 \mathrm{~min}$ \\
\hline 3 & $\begin{array}{c}150 \\
\text { (frames) }\end{array}$ & $4.5 \mathrm{~mm}$ & Forward & $5 \mathrm{~m}$ & $5 \mathrm{~min}$ \\
\hline
\end{tabular}

Table 2. Summary of the performed

flights with the related information.

\subsection{Data processing methods}

The photogrammetric workflow follows consolidated procedures and different software solutions, both open source (MicMac) and commercial (Pix4D) ones. The obtained results connected to the evaluation of the different approaches used, according to the typical accuracy evaluation that is connected to a photogrammetric process are here summarized.

MicMac is a free and open source photogrammetric suite developed by IGN and ENSG that has been selected for the data processing pipeline of this research. The operation workflow is similar to the other commercial available solutions, but all the commands are sent to the terminal using a simplified command 
line. The software covers the entire photogrammetric pipeline, from the tie-point extraction to the generation of 3D models and orthophotos. (Rupnik, Daakir and Pierrot Deseilligny, 2017).

On the other hand, Pix4D mapper pro is a commercial software, the society was founded in 2011 as a spinoff of the EPFL (École Polytechnique Fédérale de Lausanne). The program follows the standard SfM workflow and is dedicated to the processing of images for the extraction of 3D information and the traditional outputs (point cloud, mesh, DSM and orthophotos). Pix4D mapper pro works in subsequent steps for the processing of aerial images: initial processing, point cloud densification, and DSM and orthophotos generation. In the present paper the results connected to the main important issues of the photogrammetric workflow were analysed such us the GCPs and CPs accuracy the Internal Orientation Parameters and the final orthophotos.

In order to compare the above-mentioned software and to stress the achievable results for the documentation and restoration purposes, the north façade has been selected. Moreover, due to the relatively short flight time (stated on Table 3), a preliminary analysis regarding the data processing methods focuses on the use of a set of 150 frames extracted from the video (flight ID 3) captured in 1080p (Full High Definition). The analysis of a more complete dataset (obtained merging the 3 flights) will be discussed in the paragraph 4 . To orientate the photogrammetric model, a set of 6 Control Points and 3 Check Points have been used, these are both squared black and white markers, and natural points, all measured using a total station. The Points displacement and the estimated position of the cameras are showed in Figure 4. After the tie points detection, and the internal and external orientation of the cameras, it was possible to observe that the RMSE (Root Mean Square Errors) of the reprojected position of the points is slightly lower in Pix4D (Table 3).

Regarding the estimation accuracy of the Internal Orientation parameters, a GUI (Graphical User Interface) named GEMINI (Graphically Enhanced MicMac's New Interface), specifically designed for assessing the quality of photogrammetric block orientation, has been used (Calantropio et al., 2018b). The purpose of GEMINI is not only to present a user-friendly environment; its main aim is to allow the user to understand and criticise the obtained results systematically in a guided way, preserving the automation of the process.

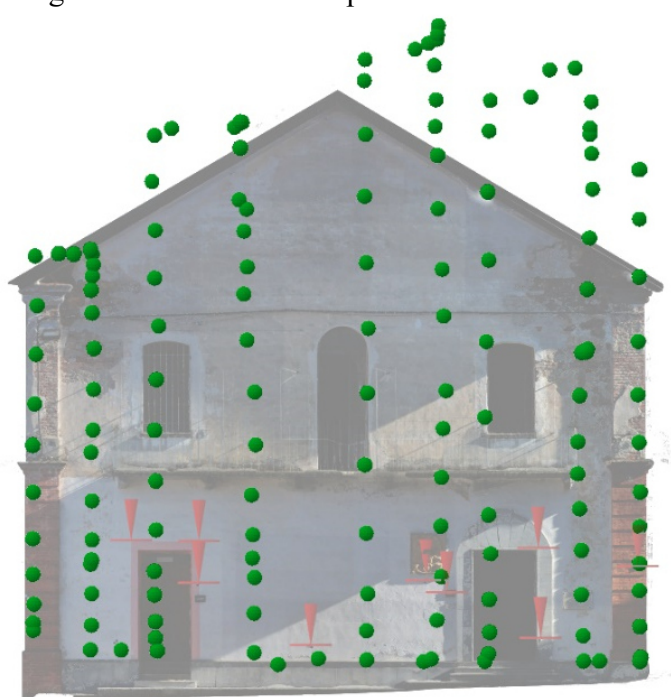

Figure 4. Map of the positions of the camera for the images captured with the flight ID $n .3$ of the DJI Spark (in green) and the position of the markers placed on the façade (in red).

\begin{tabular}{|c|c|c|c|c|c|c|}
\hline \multirow{2}{*}{ Software } & \multirow{2}{*}{$\begin{array}{c}\text { Type of } \\
\text { points }\end{array}$} & \multirow{2}{*}{$N^{\circ}$} & \multicolumn{4}{|c|}{ RMSE [mm] } \\
\cline { 4 - 7 } & & $\mathrm{X}$ & $\mathrm{Y}$ & $\mathrm{Z}$ & Total \\
\hline \multirow{2}{*}{ Pix4D } & GCPs & 6 & 6,0 & 3,2 & 4,5 & 8,2 \\
\cline { 2 - 7 } & $\mathrm{CPs}$ & 3 & 7,9 & 13,3 & 5,5 & 16,4 \\
\hline \multirow{2}{*}{ MicMac } & GCPs & 6 & 9,0 & 5,5 & 8,9 & 13,8 \\
\cline { 2 - 7 } & $\mathrm{CPs}$ & 3 & 3,4 & 16,8 & 5,2 & 17,9 \\
\hline
\end{tabular}

Table 3. Comparison of the mean errors in the three coordinate directions and for the $3 D$ component for GCPs and CPS.

According to the reported results it is possible to evaluate that both the software allows to achieve a result that is coherent with the accuracy of the scale proposed for the final products 1:100 (2 $\mathrm{cm})$.

In the Table 4 is stated a comparison of focal length and the coordinates of the principal point, according to both Pix4D and MicMac. As the two software uses different models to estimate the tangential and radial distortion, this analysis has been performed for the Internal Orientation parameters only.

Concerning the focal length and principal points coordinates the obtained results are comparable as well, a larger RMSE is evaluated in the estimation of the focal length using MicMac.

\begin{tabular}{|c|c|c|c|c|}
\hline \multirow{2}{*}{ Software } & \multirow{2}{*}{ Value } & \multicolumn{3}{|c|}{ I.O. Parameters [px] } \\
\cline { 3 - 5 } & & $\mathrm{F}$ & $\mathrm{Px}$ & $\mathrm{Py}$ \\
\hline \multirow{2}{*}{ Pix4D } & Estimated & $1.831,45$ & 964,38 & 537,43 \\
\cline { 2 - 5 } & RMSE & 2,59 & 1,25 & 1,59 \\
\hline \multirow{2}{*}{ MicMac } & Estimated & $1.844,27$ & 959,87 & 543,10 \\
\cline { 2 - 5 } & RMSE & 3,42 & 0,72 & 1,00 \\
\hline
\end{tabular}

Table 4. Comparison of focal length and the coordinates of the principal point, according to both Pix 4 D and MicMac; as an indicator of the accuracy estimation of the parameters, the RMSE of the adjusted values has been used

Another analysis performed is the comparison between the orthophotos generated using both software. The orthophotos have been generated setting a pixel size of 3,1 $\mathrm{mm}$ (Figure 5). The orthophoto produced using MicMac, although using a radiometric equalization, still suffer in some parts, as it is shown in Figure 6.

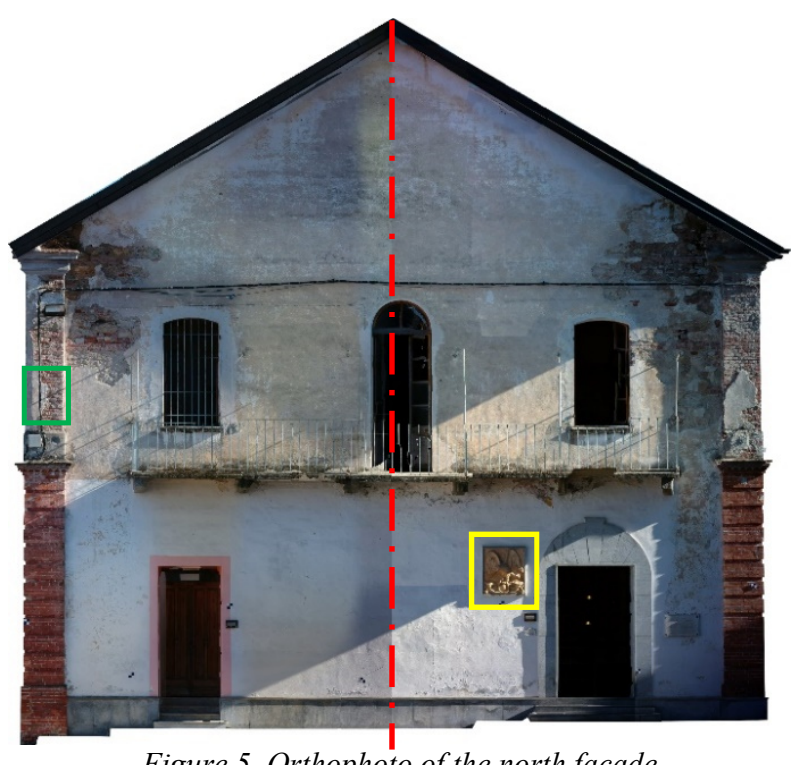

Figure 5. Orthophoto of the north façade generated using Pix4D (left) and MicMac (right) 


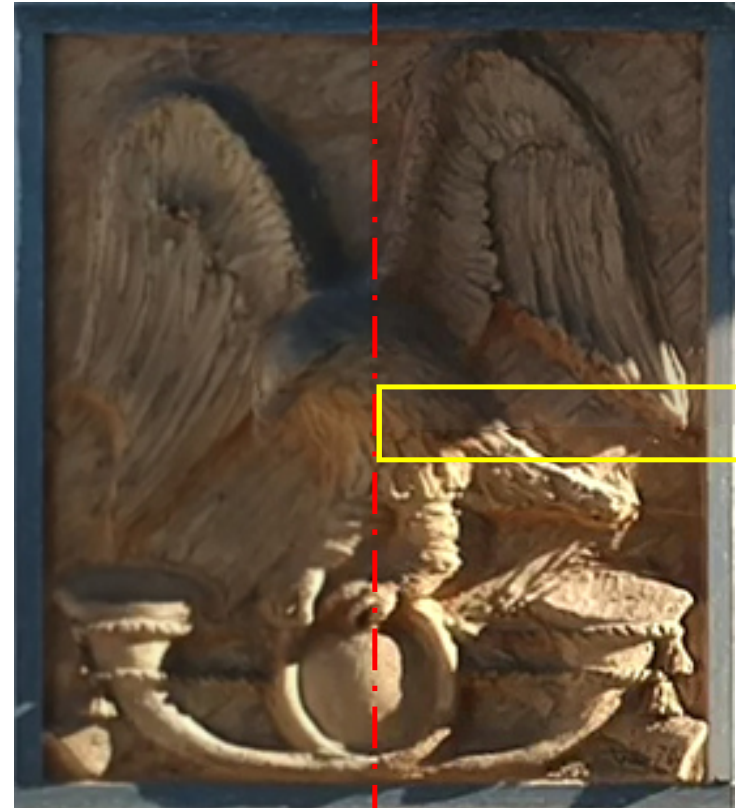

Figure 6. Orthophoto of the eagle's high relief generated using Pix4D (left) and MicMac (right). In the yellow frame it is highlighted an issue with the radiometric equalization of MicMac.

It is possible, however, to observe that the orthophoto generated using MicMac has a sharper definition of the geometric shapes with respect to the one generated by using Pix4D platform (Figure 7). This aspect could be fundamental in studying and classifying the deterioration of the façade, also for restoration purposes. Therefore, the products achievable using the two different software solutions reach a clearly acceptable level of quality.

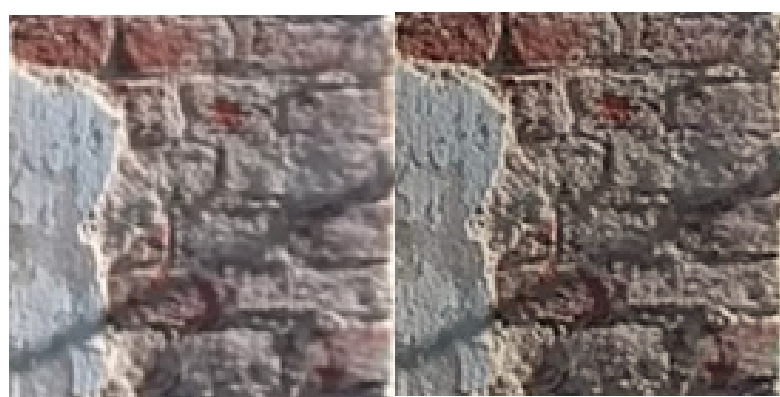

Figure 7. Detail of the façade degradation (highlighted in green in the Figure 5) for the Orthophoto generated with Pix4D (left) and MicMac (right).

\section{TERRESTRIAL LASER SCANNER: BLK360 (LEICA)}

The BLK360 (Figure 8) is the last low-cost 3D scanner commercialised by Leica. The company put a lot of effort in creating a compact product with a captivating design and userfriendly interface. In fact, the BLK is controlled by a tablet, connected through Wi-Fi, and using the Autodesk app Recap Pro interface. The operational phase on the field for the acquisition of data is simplified, also for non-expert users, and part of the processing of the data can be completed on the tablet. The compact size and manoeuvrability of the BLK360 are key factors for the employment of this sensor also in survey activities of Cultural Heritage (Zeng et al., 2018). The main specifications of the BLK360 are reported in the following Table 5. The table also report the same specifications for the Faro Focus 330: the laser produced by CAM2 was used as ground truth for the results obtained by using the BLK360.

This choice was dictated from different factors: Focus 330 is a more tested and consolidated sensors, with a slightly better ranging error and which best practice of use are more defined compared with the newest sensor of Leica.
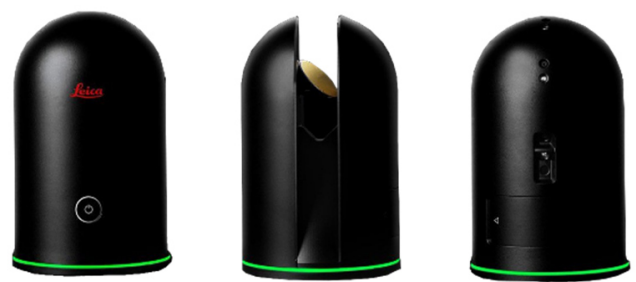

Figure 8. Leica BLK360

\begin{tabular}{|c|c|c|}
\hline TLS Model & (A) Leica BLK360 & $\begin{array}{l}\text { (B) CAM2 Faro } \\
\text { Focus }^{3 \mathrm{D}} \text { X } 330\end{array}$ \\
\hline Operational range & $0.6-60 \mathrm{~m}$ & $0.6-130 \mathrm{~m}$ \\
\hline Ranging error ${ }^{1}$ & $\pm 4 \mathrm{~mm}$ & $\pm 2 \mathrm{~mm}$ \\
\hline $\begin{array}{c}\text { Vertical/horizontal } \\
\text { FoV (Field of View) }\end{array}$ & $300 / 360^{\circ}$ & $305 / 360^{\circ}$ \\
\hline $\begin{array}{l}\text { Embedded camera } \\
\text { resolution }\end{array}$ & $\begin{array}{c}3 \times 15 \mathrm{Mpx}+\text { Thermal } \\
\text { Cam }\end{array}$ & $70 \mathrm{Mpx}$ \\
\hline Acquisition speed & up to $360.000 \mathrm{pt} / \mathrm{s}$ & up to $976.000 \mathrm{pt} / \mathrm{s}$ \\
\hline Weight & $1 \mathrm{Kg}$ & $5,2 \mathrm{Kg}$ \\
\hline Size & $165 \times 100 \times 100 \mathrm{~mm}$ & $240 \times 200 \times 100 \mathrm{~mm}$ \\
\hline
\end{tabular}

Table 5. Main specifications of the two employed laser scanners

\subsection{Acquisition strategies}

The portable Leica laser was used considering some consolidated practices (Adami, et al. 2007) for the data acquisition on the field (position of the scans, overlap of the scans, etc.). As reported in paragraph 2 for the UAVs acquisition, the metric control of all the acquired and processed laser data was granted trough the measurement of several materialized control points (markers), measured with traditional topographic solutions, that were also used to georeference the models. The main detail of the dataset acquired on the field with the two laser scanners are reported in the following Table 6 and the geometry of the scans position is showed in Figure 12.

\begin{tabular}{|c|c|c|c|c|}
\hline & $\begin{array}{c}\text { Scans } \\
{\left[\mathrm{n}^{\circ}\right]}\end{array}$ & $\begin{array}{c}\text { Mean } \\
\text { dimension } \\
{[\mathrm{MB}]}\end{array}$ & $\begin{array}{c}\text { File format } \\
{[\text {.extension }]}\end{array}$ & $\begin{array}{c}\text { Mean points } \\
{\left[\mathrm{n}^{\circ} \mathrm{pts} / \mathrm{scans}\right]}\end{array}$ \\
\hline Leica BLK360 & 8 & 1000 & $\mathrm{e} 57$ & 60.000 .000 \\
\hline $\begin{array}{c}\text { CAM2 Faro } \\
\text { Focus3D X 330 }\end{array}$ & 10 & 400 & $\mathrm{e} 57$ & 16.000 .000 \\
\hline
\end{tabular}

Table 6. Main details of the two TLS dataset

It is necessary to underline that the two instruments were used following the same acquisition schema, but the parameters adopted for the two lasers are different. This issue, that results in a disparity of the mean number of points per scan acquired by the two sensors, is related mainly with the will of testing the BLK360 at its best possibilities, due to its very first use by the authors. This issue was obviously considered during the subsequent analyses in order not to affect the final results.

\subsection{Data processing methods}

The processing of the acquired data was conducted adopting two different solution: the automate process through the dedicated app (Autodesk Recap) and an ad hoc procedure using other 
commercial software. The two different strategies and the obtained products were then compared, in order to evaluate the achievable results applying different approaches. The two datasets were processed using the software solution suggested from the producers of the two instruments: Faro Scene for the Focus 330 and Autodesk Recap Pro for the BLK360. For both the solutions the first step was related with a C2C (Cloud to Cloud) registration of the different scans through an ICP (Iterative Closest Point) algorithm, however the approach and the workflow embedded in the two solutions is slightly different. In the Scene software the first part of the $\mathrm{C} 2 \mathrm{C}$ alignment is left to the manual intervention of the operator that perform a rough alignment of the different scans (manually translating the relative position of the scans in the space) in order to reduce the computational phase of the software. In the Autodesk software part of this process can be performed on the field on the tablet connected with the BLK360 and the optimize results of this procedure are also downloaded on the desktop software. If the operator decides not to perform this pre-processing on the field or to not use the solution proposed by the computation realized on the mobile app, is possible to start with the registration on the desktop software. The first approach proposed by Recap is a fully automated solution that requires a long computational time (obviously time-dependent and exponential to the number of scans) that look for matches in all the scans of the dataset. If the procedure is not fully successful, the software asks the operators to select common point between the scans (three - no more and no less) or to highlight targets (chessboard or spherical), in order to use them to enhance the $\mathrm{C} 2 \mathrm{C}$ registration. The second part of the workflow is, in both the software, dedicated to georeferencing of the scans trough the input of survey points and coordinates. In this phase the Scene software offers a better control to the operator, allowing the possibility to rigidly block the previously registered scans, to use the points to perform a rototranslation, without changing the relative position of the scans. In the Autodesk app the control that the operator can have on the GCPs is weaker and their insertion in the software is more complicated. Also considering these issues the comparison between the two processed datasets was quite surprising. A C2C distance analysis performed in Cloud Compare lead to the results reported in the following Table 7; Figure 9 shows a preview of the registered scans using Autodesk Recap Pro

\begin{tabular}{|c|c|c|}
\hline Sensor & $\begin{array}{c}\text { Mean Scan } \mathrm{pt} \text { Tension } \\
{[\mathrm{mm}]}\end{array}$ & $\begin{array}{c}\text { Scan pt tension }<\mathrm{x}^{1} \mathrm{~mm} \\
{[\%]}\end{array}$ \\
\hline Leica BLK360 & -2 & 98 \\
\hline $\begin{array}{c}\text { CAM2 Faro } \\
\text { Focus3D X 330 }\end{array}$ & 4,58 & 49.5 \\
\hline $\begin{array}{l}{ }^{1} \mathrm{x}=4 \text { for CAM2 Faro Focus3D X 330 and } \\
\mathrm{x}=6 \text { for Leica BLK360 } \\
{ }^{2} \text { Mean scan point tension is not provided by Autodesk Recap Pro }\end{array}$ \\
\hline
\end{tabular}

Table 7. Results of point tension between the clouds after the registration

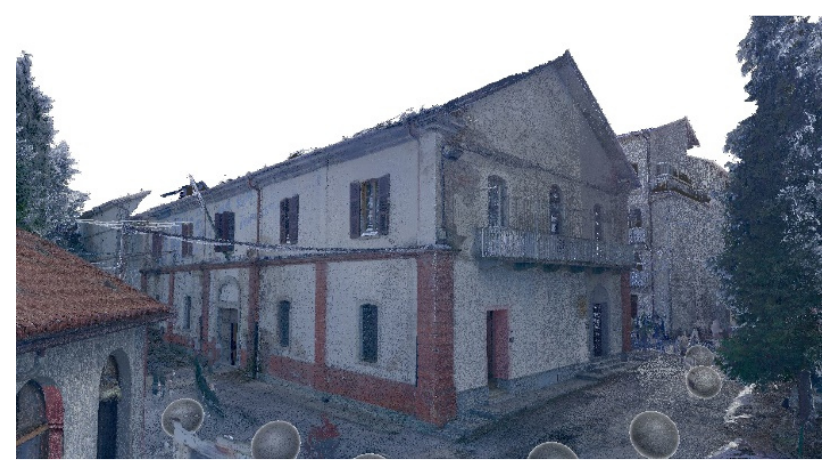

Figure 9. Preview of the scans from BLK360

\section{Sensors' Evaluation: range-based vs image-based}

In the following paragraphs, some results are proposed trough benchmarking the performances of both sensors in different modalities, and considering factors affecting data quality, together with the geometric properties of the resulting 3D products.

\subsection{Product comparison}

For the sensor's evaluation, a C2C comparison has been performed for the point clouds generated using the data from DJI Spark and the one obtained using the BLK360, both considering the Faro Focus 330 as ground truth. All the analysis presented in this subchapter are referred to the considered north-east corner of the building, Figure 10 and 12 shows the results of an absolute distance (threshold $<30 \mathrm{~mm}$ ), with means and standard deviations of the values reported in Table 8.

\begin{tabular}{|c|c|c|}
\hline & Mean [mm] & Std. dev. [mm] \\
\hline $\begin{array}{c}\text { DJI Spark vs } \\
\text { CAM2 Faro Focus3D X 330 }\end{array}$ & 11.5 & 8.4 \\
\hline $\begin{array}{c}\text { Leica BLK360 vs } \\
\text { CAM2 Faro Focus3D X 330 }\end{array}$ & 4.9 & 3.5 \\
\hline
\end{tabular}

Table 8. Statistical synthesis of the cloud-to-cloud absolute distance computation $(<30 \mathrm{~mm})$ for the two performed analysis.

In Figure 11 the positions of the cameras' centres are marked, together with the position of the GCPs and CPS on the façade used for georeferencing the models. Figure 13 shows the physical positions of the scans with both the TLSs considered. A density analysis performed on the point clouds underlines that the number of neighbours is slightly higher for the BLK360 (Table 9); this is likely related to the settings of the scans (higher for the BLK360).

\begin{tabular}{|c|c|c|c|}
\hline & $\begin{array}{c}\text { Cloud size } \\
{[\mathrm{n} . \mathrm{pts}]}\end{array}$ & $\begin{array}{c}\text { Mean } \\
{[\mathrm{n} . \mathrm{pts}]}\end{array}$ & $\begin{array}{c}\text { Std. dev. } \\
{[\mathrm{n} . \mathrm{pts}]}\end{array}$ \\
\hline DJI Spark & 14.032 .143 & 10.70 & 7.21 \\
\hline Leica BLK360 & 40.296 .102 & 56.03 & 26.51 \\
\hline CAM2 Faro Focus3D X 330 & 12.960 .165 & 13.48 & 8.42 \\
\hline \multicolumn{2}{|c|}{ Table 9. Density (Number of neighbours) calculated by pt/V. }
\end{tabular}

analysing a sphere with a radius of $10 \mathrm{~mm}$.

For normalizing these observations, a series of density analysis have been performed for a sample of $1 \mathrm{~m}^{2}$ of façade at $2 \mathrm{~m}$ and $8 \mathrm{~m}$ of height (Table 10). The ratio between the two density shows a normalized decrease of density, independent to the quality settings of the TLS. The density analysis has been performed also on the detail showed in Figure 6.

\begin{tabular}{|c|c|c|c|c|}
\hline & $\begin{array}{l}\text { Sample density } \\
{\left[\mathrm{pts} / 0,66 \mathrm{~m}^{2}\right]}\end{array}$ & $\begin{array}{c}\text { Lower } \\
\text { Part }^{2} \\
{\left[\mathrm{pts} / \mathrm{m}^{2}\right]}\end{array}$ & $\begin{array}{c}\text { Higher } \\
\text { part }^{3} \\
{\left[\mathrm{pts} / \mathrm{m}^{2}\right]}\end{array}$ & $\begin{array}{c}\mathrm{H} / \mathrm{Q} \\
\text { density } \\
\text { ratio }\end{array}$ \\
\hline DJI Spark & 34.927 & 30.800 & 23.594 & $76 \%$ \\
\hline $\begin{array}{c}\text { Leica } \\
\text { BLK360 }\end{array}$ & 189.191 & 250.086 & 92.164 & $37 \%$ \\
\hline $\begin{array}{c}\text { Faro } \\
\text { Focus3D X } \\
\mathbf{3 3 0}\end{array}$ & 64.046 & 84.685 & 36.718 & $43 \%$ \\
\hline \multicolumn{5}{|c|}{$\begin{array}{l}{ }^{1} \text { According to the sample area (the eagle's high relief). } \\
{ }^{2} \mathrm{~A} \text { sample of } 1 \mathrm{~m}^{2} \text { of plan façade measured at } 2 \mathrm{~m} \text { height (from the centre of } \\
\text { the square to the ground). } \\
{ }^{3} \mathrm{~A} \text { sample of } 1 \mathrm{~m}^{2} \text { of plan façade measured at } 10 \mathrm{~m} \text { height (from the centre of } \\
\text { the square to the ground). }\end{array}$} \\
\hline
\end{tabular}

Table 10. Analysis on the samples area of the case study according to the three sensors. 


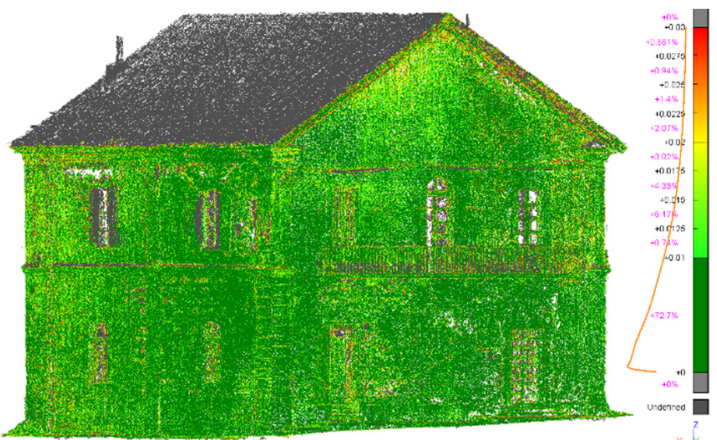

Figure 10. C2C comparison between the X330 point cloud (ground truth) and the DJI Spark for an absolute distance $<30$ $\mathrm{mm}$

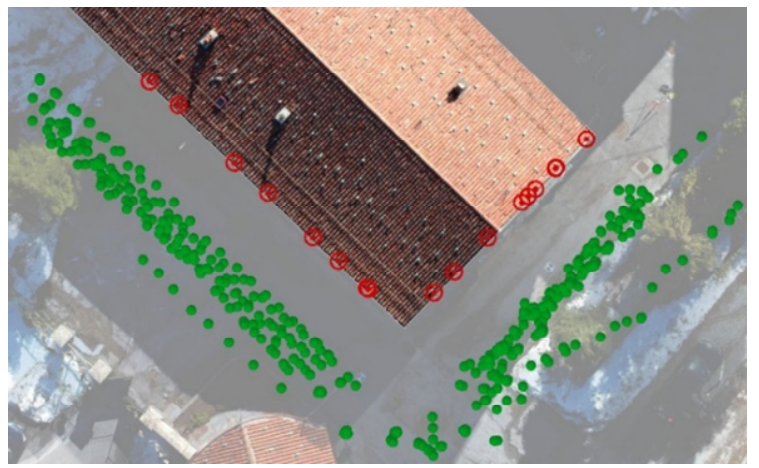

Figure 11. Positions of the camera for the images captured with the DJI Spark (green) and the markers placed on the façade (red).

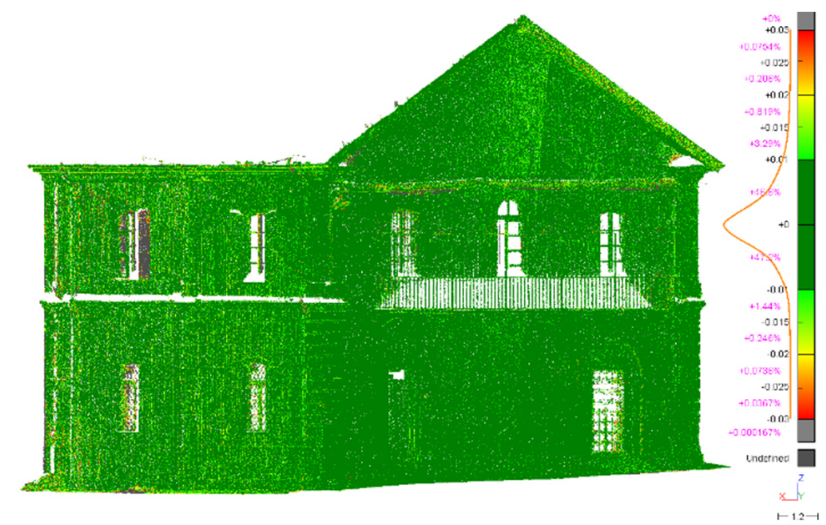

Figure 12. C2C comparison between the X 330 point cloud (ground truth) and the BLK360 for an absolute distance $<30 \mathrm{~mm}$.

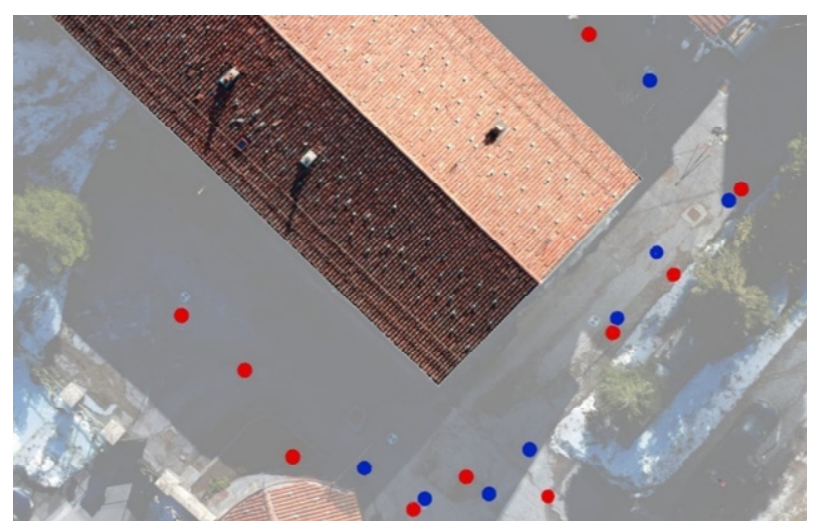

Figure 13. Positions of the X 330 scans (red) and the BLK360 scans (blue).
Furthermore, starting from the general objective of an architectural survey that require the realization of traditional sections, plans and façade, the automatic extraction of 2D data from the point clouds has been performed. Comparing the different generated clouds and the connected extracted sections is possible to state, as is shown in Figure 14, that all the three results are comparable. Naturally where an area present high discontinuity an accurate check on the resulted 2D section need to be performed in order to describe in the correct way the geometry of the surveyed object.
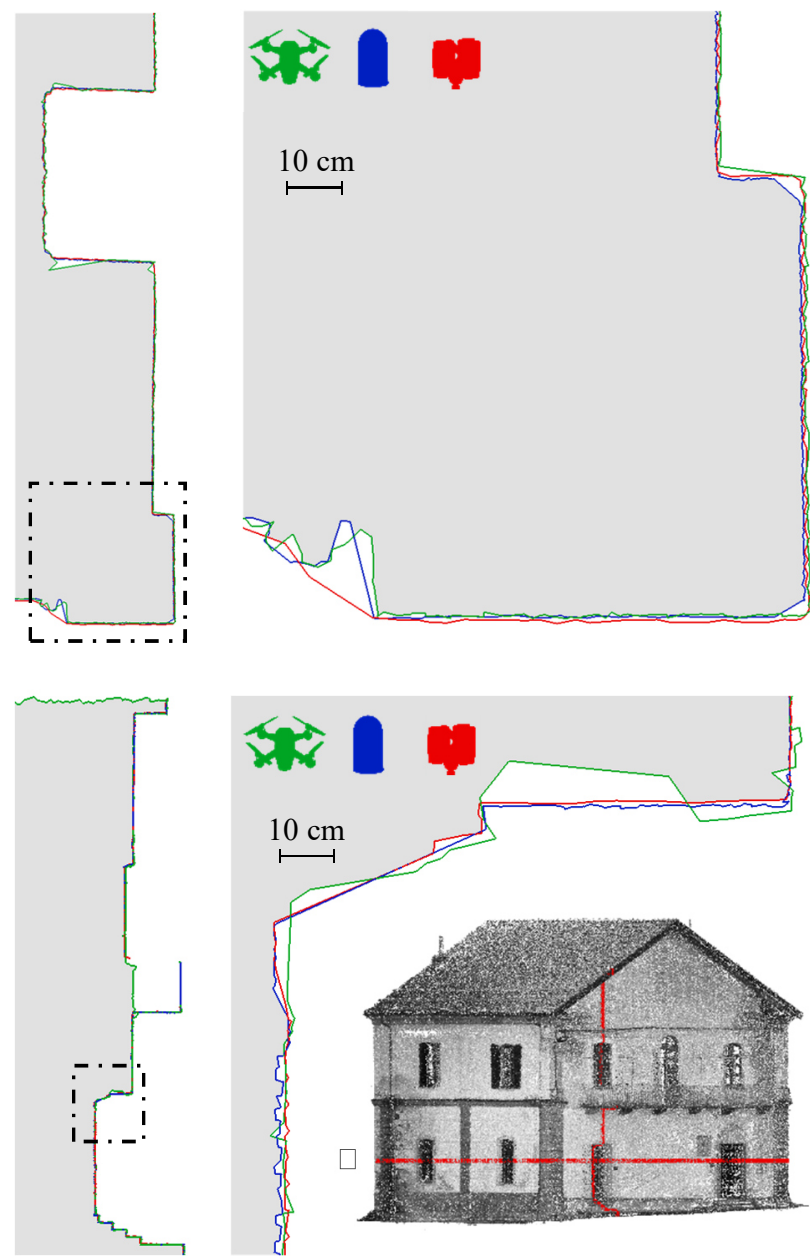

Figure 14. Plan section ( $A$ - top) and cross section ( $B$ - bottom) of the north façade of the barracks. The coloured lines represent the section extracted from the models generated using: DJI Spark (in green), Leica BLK360 (in blue) and the Faro Focus 330 (in red).

\subsection{Photogrammetry and LiDAR: data integration}

The typical question: "which sensor or approach is better?" is no longer relevant nowadays. According to the actual direction of research and development in the field of Built Heritage documentation, and to the related quality of the achievable products, the current trend aims towards a complete integration between photogrammetry and LiDAR. The two different techniques contribute with the same weight to the documentation phase, since where there is a weakness in the employment of LiDAR, it is possible to successfully supply with a strength of photogrammetry, and vice versa; the possibility to acquire data in critical parts of the object not easily recorded by LiDAR, such as roof or eaves, can be gathered by UAVs and processed using photogrammetric approach and, furthermore, integrated in the 
final point cloud. When there is the need to realize a very accurate 3D model, it is possible to use LiDAR data for the meshing phase and, then, apply the texture obtained from the photogrammetric data, as the images acquired by the LiDAR are usually at a lower resolution compared with the photogrammetric ones.

The complete data integration, in terms of sensors and related products, currently allows to obtain products that fulfils the general requirements of a survey connected to the architectural documentation (e.g. the use of low cost equipment, the controlled accuracy in terms of precision, the reliability and the subsequent achievable level of detail, a fast acquisition, flexibility and according to the dimension of the tested instrument - its interesting portability).

The integration of the data acquired by range and image-based sensors allows to easily obtain 3D point clouds, 3D textured models and orthophotos that have improved a lot the documentation pipeline in the knowledge of Cultural Heritage artefacts. The actual bottleneck is still related to the generation of the final 2D drawings that, despite the continuous development of new automatic algorithms, is always connected to the operator who needs (starting from the sections obtained by the 3D data) to "read" the architecture that characterize the object and finally, using the extracted data, define the correct 2D representation.

\section{CONCLUSIONS}

The portability of the BLK360, together with its relative low market price (compared with the other available TLS), makes it a good solution for professionals and scientists in scenarios where the lightweight of the instrument and the acquisition time are important factors for the survey operations.

Regarding the DJI Spark, the environmental limits (narrow space, proximity of trees, etc.) makes it a valid alternative to bigger UAVs in case of acquisition of façade images for photogrammetric purposes. Indeed, the use of widely available, ease to use and relatively low-cost platforms are key factors that contribute to the dissemination of learning and teaching material on the use of UAV and range-sensors in Academia. Moreover, due to the current legislation in the UE countries, the reduced weight of these aerial platforms fulfils the strict regulatory limits. The Table 11 summarizes the characteristics of the employed sensors in terms of price, acquisition and processing steps and quality of the achievable results.

The analysed sensors, especially the Leica BLK360, needs further tests in different conditions and for other purposes (e.g. thermal survey), that will be in deep investigated in the future works of the authors.

\begin{tabular}{|c|c|c|c|c|c|c|c|c|c|}
\hline \multirow[b]{2}{*}{ Sensors } & \multirow[b]{2}{*}{ Price } & \multicolumn{3}{|c|}{ Acquisition } & \multicolumn{3}{|c|}{ Processing } & \multicolumn{2}{|c|}{ Results } \\
\hline & & $\begin{array}{c}\text { Battery } \\
\text { life }\end{array}$ & $\begin{array}{l}\text { Acquisition } \\
\text { time }\end{array}$ & $\begin{array}{c}\text { Operator } \\
\text { work }\end{array}$ & $\begin{array}{c}\text { Hardware } \\
\text { load }\end{array}$ & User Work & Processing time & LOD & Noise \\
\hline DJI Spark & (\$) & 商 & (1) & 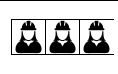 & 凰 & 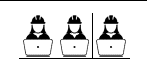 & (圆) (圆) (圆) & In & ن \\
\hline Leica BLK360 & 国 & 䚩 & (1)(5) & 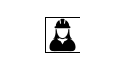 & 间o & \begin{tabular}{|l|l|}
$*$ & $*$ \\
\end{tabular} & (圆) (圆) & pli & $x$ \\
\hline $\begin{array}{c}\text { CAM2 Faro } \\
\text { Focus3D X } 330\end{array}$ & 回 & 百解 & (D)(D)(b) & 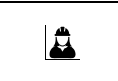 & 目 & 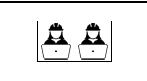 & (困) (圆) & I & \\
\hline
\end{tabular}

Table 11. Summarization of the characteristics of the employed sensors which influences the quality of the results, the user experience during the acquisition and the processing phases and the hardware efficiency.

\section{ACKNOWLEDGEMENTS}

The authors would like to thank the Municipality of Mondovì for allowing the realisation of the survey. The authors would also like to thank Professors Paolo Piumatti and Cesare Tocci of Politecnico di Torino who co-teaches in the Course of "New Technology for Surveying and Drawing" and participated in the survey activities. Part of this research has been supported and funded by the GAMHer project (Geomatics data Acquisition and Management for landscape and built Heritage in a European perspective), a 3-year project financed under the Italian PRIN 2015 framework (Progetti di Ricerca di Rilevante Interesse Nazionale).

\section{REFERENCES}

Achille, C., Fassi, F., Mandelli, A., \& Fiorillo, F. (2018). Surveying cultural heritage: summer school for conservation activities. Applied Geomatics.

Adami, A., Guerra, F., \& Vernier, P. (2007). Laser Scanner and Architectural Accuracy Test. Proceedings of XXI Intl CIPA Symposium, (October), 5 pp.

Calantropio, A., Deseilligny, M. P., Rinaudo, F., and Rupnik, E. (2018b) Evaluation Of Photogrammetric Block Orientation Using Quality Descriptors From Statistically Filtered Tie Points, Int. Arch. Photogramm. Remote Sens. Spatial Inf. Sci., XLII-2, 185-191, 2018.

Calantropio, A., Chiabrando, F., Sammartano, G., Spanò, A., \& Losè, L. T. (2018). UAV strategies validation and remote sensing data for damage assessment in post-disaster scenarios. International Archives of the Photogrammetry, Remote Sensing and Spatial Information Sciences -
ISPRS Archives, 42(3W4), 121-128.

Fassi, F., Fregonese, L., Ackermann, S., \& De Troia, V. (2013). Comparison Between Laser Scanning and Automated 3D Modeling Techniques To Resconstruct Complex and Extensive Cultural Heitage Areas. International Archives of Photogrammetry and Remote Sensing, XL-5/W1(February), 7380 .

Hess, M., Petrovic, V., Yeager, M., \& Kuester, F. (2018). Terrestrial laser scanning for the comprehensive structural health assessment of the Baptistery di San Giovanni in Florence, Italy: an integrative methodology for repeatable data acquisition, visualization and analysis. Structure and Infrastructure Engineering, 14(2), 247-263.

Rupnik, E., Daakir, M., \& Pierrot Deseilligny, M. (2017). MicMac - a free, open-source solution for photogrammetry. Open Geospatial Data, Software and Standards, 2(1), 14.

Russo, M., Carnevali, L., Russo, V., Savastano, D., \& Taddia, Y. (2018). Modeling and deterioration mapping of façades in historical urban context by close-range ultra-lightweight UAVs photogrammetry. International Journal of Architectural Heritage, 00(00), 1-20.

Soudarissanane, S., Lindenbergh, R., Menenti, M., \& Teunissen, P. (2011). Scanning geometry: Influencing factor on the quality of terrestrial laser scanning points. ISPRS Journal of Photogrammetry and Remote Sensing, 66(4), 389-399.

Stöcker, C., Bennett, R., Nex, F., Gerke, M., \& Zevenbergen, J. (2017). Review of the current state of UAV regulations. Remote Sensing, 9(5), 33-35.

Zeng, X., Cui, L., Tan, Q., Li, Z., \& Huang, G. (2018). Cultural Heritage Conservation and Sustainability Based on Surveying and Modeling: The Case of the 14th Century Building Corral del Carbón (Granada, Spain). Sustainability (Switzerland), 10(5). 